\title{
Crack patterns corresponding to the residual strength plateau of ceramics subjected to thermal shock
}

\author{
H.-L. Hou · X.-F. Wu · P. Yan · F. Song · J. Li · C.-P. Jiang
}

Received: 3 June 2011 / Revised: 10 November 2011 / Accepted: 5 January 2012

(C)The Chinese Society of Theoretical and Applied Mechanics and Springer-Verlag Berlin Heidelberg 2012

\begin{abstract}
The formation mechanism of the residual strength plateau of ceramics subjected to thermal shock is addressed. A set of thermal shock experiments of $99 \mathrm{Al}_{2} \mathrm{O}_{3}$ are conducted, where the thin specimens of $1 \mathrm{~mm} \times 10 \mathrm{~mm} \times 50 \mathrm{~mm}$ exhibit parallel through edge cracks, and thus permit quantitative measurements of the crack patterns. The cracks evolve with the severity of thermal shock. It is found that there is a correlation between the length and density of the thermal shock cracks. The increase of crack length weakens the residual strength, whereas the increase of crack density improves it. In a considerably wide temperature range, the two contrary effects just counteract each other; consequently a plateau appears in the variation curve of the residual strength. A comparison between the numerical and experimental results of the residual strength is made, and they are found in good agreement. This work is helpful to a deep understanding of the thermal shock failure of ceramics.
\end{abstract}

Keywords Ceramics - Thermal shock - Crack patterns . Residual strength $\cdot$ Stress intensity factor

The project was supported by the National Natural Science Foundations of China (10972020, 11061130550), the Fundamental Research Funds for the Central Universities and the National Agency for Research of France (International project T-shock).

H.-L. Hou · X.-F. Wu · P. Yan · C.-P. Jiang $(\varangle)$

School of Aeronautic Science and Engineering,

Beihang University, 100191 Beijing, China

e-mail: jiangchiping@buaa.edu.cn

F. Song

State Key Laboratory of Nonlinear Mechanics (LNM), Institute of Mechanics, Chinese Academy of Sciences, 100190 Beijing, China

J. Li

LSPM, CNRS UPR 3407, Université Paris XIII,

99 Avenue Jean-Baptiste Clément,

93430 Villetaneuse, France

\section{Introduction}

Ceramic materials have been widely used in thermostructural engineering due to their excellent high temperature performance $[1,2]$. However, their inherent brittleness and poor resistance to thermal shock have slowed their use. Many researchers focused on problems of ceramic thermal shock failure.

Kingery [3] investigated the sources and calculation of thermal stresses and also considered the factors affecting the thermal stress resistance of ceramics. Hasselman [4] examined the strength behavior of polycrystalline alumina subjected to thermal shock. Gupta [5] showed that the strength degradation and crack propagation in $\mathrm{Al}_{2} \mathrm{O}_{3}$ depend on the initial strength and grain size of the material. Davidge [6] experimentally studied the minimum shock to produce the first cracking and the amount of damage produced by a shock of a given severity, using a dye-penetrant method and measurements of fracture stress before and after shock. Coppola [7] studied the thermal shock strength loss of ceramic circular rods and obtained an empirical formula which revealed that the residual strength is proportional to the crack density with a power of $1 / 4$. Bertsch [8] examined $\mathrm{Al}_{2} \mathrm{O}_{3}$ circular rods quenching, respectively, in water and silicone oil and found that rods with denser cracks would exhibit higher strength, even up to a factor of 2. Zhang [9] investigated $\mathrm{Al}_{2} \mathrm{O}_{3}$ thick strip quenching at different temperatures and conducted statistical analysis of crack distribution as well as bending test. Jin et al. [10-13] numerically studied elastic strips with different crack patterns (different crack length, spacing etc.) to examine the relationship among changes in quenching temperature, variations in spacing and penetration, and thermal stress intensity factors.

Scholars very early noticed that there is a plateau in the residual strength curves of ceramics subjected to thermal shock [4, 5, 14]. As shown in Fig. 1, when the temperature difference, $\Delta T$, of thermal shock is less than a certain critical value, $\Delta T_{\mathrm{c}}$, the ceramic strength remains unchanged. Just across $\Delta T_{\mathrm{c}}$, however, the strength suddenly decreases to 
a very low value. Then an interesting phenomenon appears: with the further increase of $\Delta T$, both the length and density of the thermally shocked cracks increase, but the residual strength of the specimen remains unchanged in a considerably wide range. A study on the formation of such a residual strength plateau is helpful to the understanding of the failure mechanism of ceramics subjected to thermal shock. However, quantitative relations between the residual strength and the crack patterns have not been reported yet, which is the purpose of the present work.

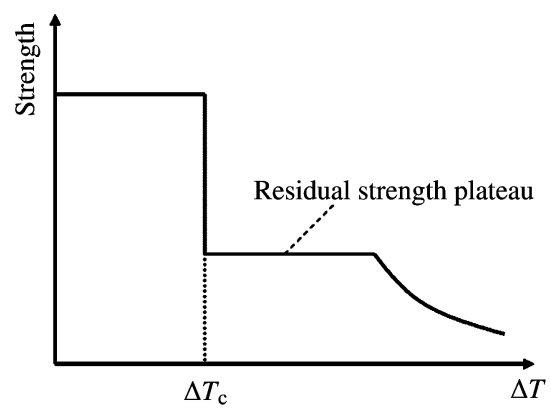

Fig. 1 Thermal shock residual strength curve

From previous experiments $[4,6,9,15]$, it is observed that the thermal shock cracks are generally not through cracks, and have complex 3-dimensional geometry, which prohibits a quantitative study to a great extent. To overcome this difficulty, by adopting thin ceramic specimens, a set of new thermal shock experiments are conducted. It shows that the thermal shock cracks are rather regular parallel through cracks, which permits quantitative measurements and analyses.

\section{Experimental}

\subsection{Thermal shock experiment}

The thin ceramic specimens studied here are made of $99 \mathrm{Al}_{2} \mathrm{O}_{3}$ with the dimensions of $1 \mathrm{~mm} \times 10 \mathrm{~mm} \times 50 \mathrm{~mm}$. The surfaces of all specimens were deliberately polished. Then they were stacked together in sets of five plus two outmost thick ceramic plates for heat insulation. Finally they were tied up firmly by inconel wires. Each set of specimens were heated in a furnace with temperature controller at the rate of $10{ }^{\circ} \mathrm{C} / \mathrm{min}$ to a preset temperature and held for 20 min at this temperature. After that, the heated specimens were immediately dropped into a water bath of $20^{\circ} \mathrm{C}$ by free fall from a height of $50 \mathrm{~mm}$, at the same time the cooling water was continuously stirred for $10 \mathrm{~min}$, then specimens were taken out and dried at $110{ }^{\circ} \mathrm{C}$ for $1 \mathrm{~h}$, and finally infiltrated in ink for $24 \mathrm{~h}$ to dye cracks that were formed during water quenching $[9,16]$. The digitally scanned photographs of thermal shock cracks are shown in Fig. 2.

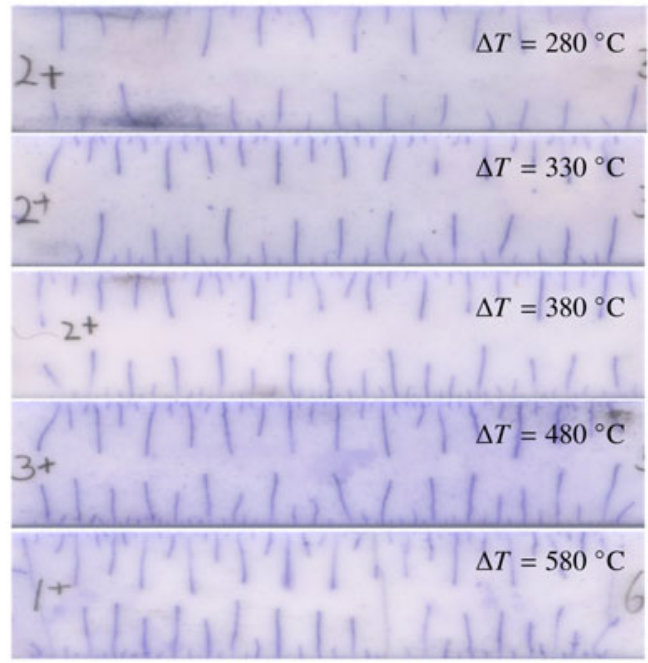

Fig. 2 Thermal shock crack patterns of specimens at different values of $\Delta T$

\subsection{Crack length and spacing}

As shown in Fig. 2, the thermal shock cracks in the thin specimens are rather regular through cracks, which permits quantitative measurements of the crack length and spacing. To remove end effect, the chosen area is the middle area of length $0.6 L$, where $L$ is the total length of a specimen. It is seen from Fig. 2 that the thermal shock cracks are hierarchical in length and the residual strength is dominated by long cracks, so only the cracks which are not less than $50 \%$ of the longest crack are counted and measured. The statistical values of the crack length and spacing versus the thermal shock temperature difference $\Delta T$ are displayed in Fig. 3. It is seen that the higher the $\Delta T$, the longer the cracks and the less the crack spacing.
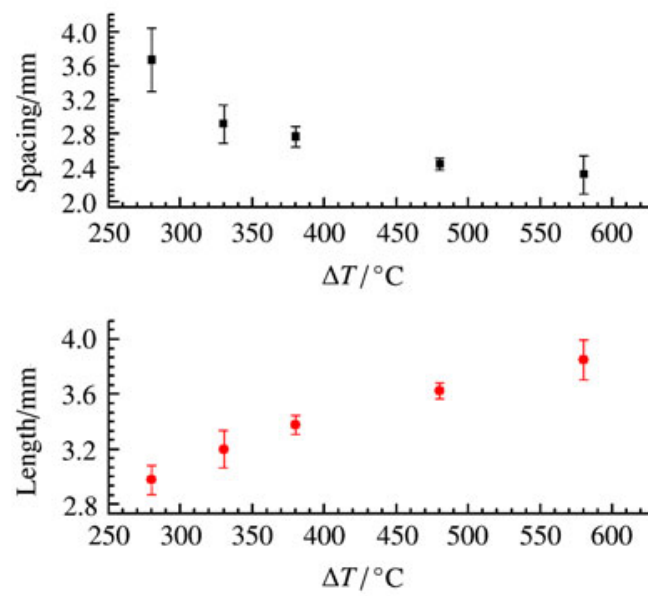

Fig. 3 The length and spacing of thermal shock cracks at various values of thermal shock temperature difference $\Delta T$ 


\subsection{Residual strength}

The residual strength of the thermally shocked specimens was measured at room temperature by a three-point bending test. The loading is controlled by displacement with a total span of $30 \mathrm{~mm}$. The crosshead speed of the micromechanical material testing machine is $0.5 \mathrm{~mm} / \mathrm{min}$ and the load sensor range is $\pm 250 \mathrm{~N}$. In the test no subcritical propagation of the thermal shock cracks was observed and the observation was confirmed by a sudden drop of the load-displacement curve. The reason is the inherent brittleness of ceramics and the fact that the residual strength is determined by long thermal shock cracks. The testing results are listed in Table 1.

Table 1 Room-temperature strengths of thermally shocked ceramic specimens at various values of thermal shock temperature difference $\Delta T$

\begin{tabular}{cl}
\hline$\Delta T /{ }^{\circ} \mathrm{C}$ & Flexural strength/MPa \\
\hline 0 & $442.700 \pm 2.018$ \\
220 & $442.700 \pm 2.018$ \\
250 & $84.473 \pm 8.842$ \\
280 & $68.231 \pm 2.651$ \\
330 & $62.379 \pm 9.303$ \\
380 & $59.818 \pm 10.95$ \\
480 & $64.558 \pm 12.375$ \\
580 & $59.811 \pm 7.000$ \\
680 & $8.146 \pm 1.123$ \\
\hline
\end{tabular}

Table 1 indicates that when the thermal shock temperature difference $\Delta T$ is less than $220^{\circ} \mathrm{C}$, the strength of ceramic specimens remains unchanged and no cracks appear in the specimens. When $\Delta T$ increases from $220^{\circ} \mathrm{C}$ to $250{ }^{\circ} \mathrm{C}$, the strength suddenly decreases to a very low value and cracks appear; Then when $\Delta T$ increases from $250{ }^{\circ} \mathrm{C}$ to $580{ }^{\circ} \mathrm{C}$, the residual strength remains unchanged again. In such a considerably wide range of $\Delta T$, the residual strength curve exhibits a plateau, but cracks evolve by getting longer and denser (less spacing). This work concerns with the formation mechanism of such a plateau.

\section{Numerical study}

Now we study the formation mechanism of the residual strength plateau by applying fracture mechanics and finite element analysis. The specimens in a three-point bending test (Fig. 2) can be modeled by an elastic strip with an array of periodic edge cracks as shown in Fig. 4, where $L_{1}=30 \mathrm{~mm}$ is the span between two supports, $L_{2}=10 \mathrm{~mm}$ the distance of a support to the lateral side, $H=10 \mathrm{~mm}$ the strip height, $a$ the average length of long cracks and $s$ the average spacing. The strip thickness is $W=1 \mathrm{~mm}$. Since the cracks on the upper side are in compression, they have no effect on stresses and are not considered.

For a three-point bending test of a specimen with edge cracks, the nominal maximum stress can be calculated as

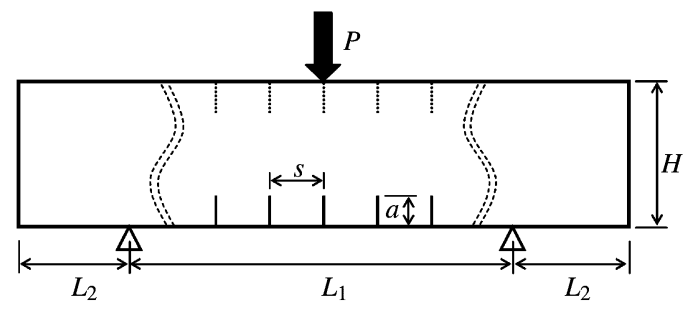

Fig. 4 A thermally shocked elastic strip with an array of periodic edge cracks

$\sigma_{\max }=\frac{3}{2} \frac{P L_{1}}{W H^{2}}$

where $L=L_{1}+2 L_{2}, P$ is the load. The residual strength $\sigma_{\mathrm{R}}$ is defined as the value of the nominal maximum stress $\sigma_{\max }$ when the specimen breaks. In finite element analysis, we firstly calculate the stress intensity factor, then determine the critical value of $P$ when the maximum stress intensity factor (SIF) reaches the fracture toughness of the material, finally calculate the residual strength $\sigma_{\mathrm{R}}$ by using Eq. (1).

To improve accuracy and efficiency, a crack tip singular element is inserted into the commercial software ANSYS, and PLANE82 element is employed in the quasi-static simulation. For the convenience of comparison, all the parameters are nondimensionalized as

$a^{*}=a / H, \quad L^{*}=L_{1} / H, \quad s^{*}=s / H, \quad K^{*}=\frac{2 W H^{2} K}{3 L_{1} P \sqrt{\pi a}}$,

and the density of thermal shock cracks $d^{*}$ is defined as

$d^{*}=1 / s^{*}$.

To check the correctness of the developed program, a comparison of results obtained in this work with those in Ref. [17] is listed in Table 2. Good agreement is observed.

Table 2 Nondimensional stress intensity factors for single edge cracked specimens in three-point bending

\begin{tabular}{ccccc}
\hline \multirow{2}{*}{$a^{*}$} & \multirow{2}{*}{$L^{*}$} & \multicolumn{2}{c}{$K^{*}$} & \multirow{2}{*}{ Relative error/\% } \\
\cline { 3 - 4 } & & Present & Reference [17] & \\
\hline 0.10 & 4 & 1.74577 & 1.73913 & 0.38173 \\
0.15 & 4 & 1.72474 & 1.72084 & 0.22667 \\
0.20 & 4 & 1.73760 & 1.73376 & 0.22164 \\
0.25 & 4 & 1.77906 & 1.77482 & 0.23893 \\
0.30 & 4 & 1.84771 & 1.84405 & 0.19852 \\
\hline
\end{tabular}

Figure 5a shows the variation of residual strength $\sigma_{\mathrm{R}}$ with the crack length for various values of crack spacing. Figure $5 \mathrm{~b}$ indicates the variation of the residual strength $\sigma_{\mathrm{R}}$ with the crack density for various values of the crack length. It is observed that the increase of the crack length weakens the residual strength, whereas the increase of the crack density improves it. 

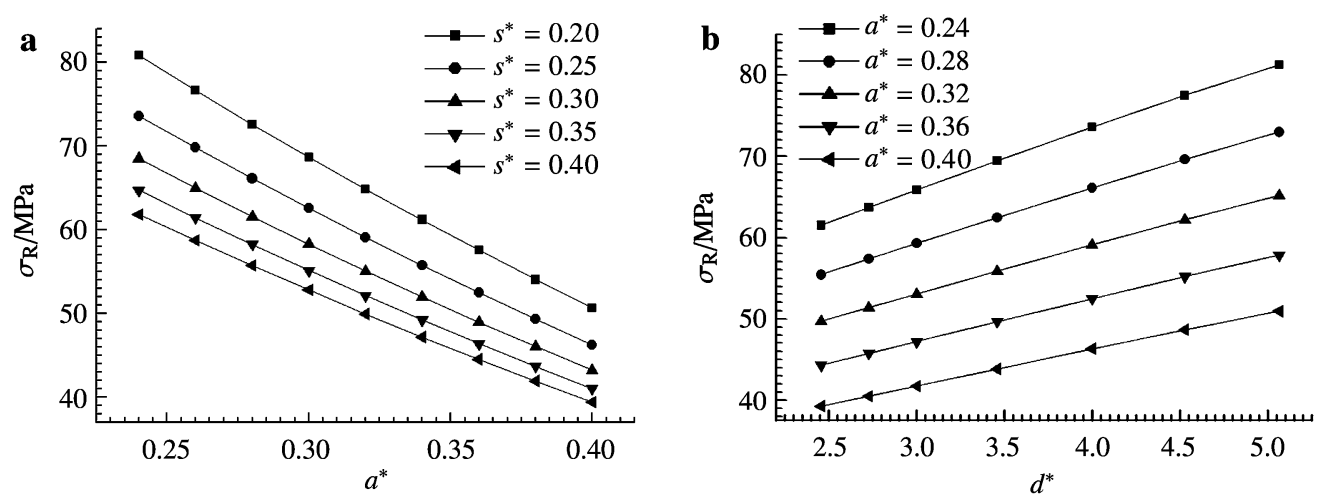

Fig. 5 Residual strength $\sigma_{\mathrm{R}}$ versus crack length $a^{*}$ and density $d^{*}$ (spacing $s^{*}$ ) at various values of thermal shock temperature difference $\Delta T$

\section{Comparison between the numerical and experimental results}

Figure 5 indicates that the increase of the crack length and density has contrary effects on the residual strength, which provides a hint that there is a correlation between the length and density (or spacing) of thermal shock cracks. Such a correlation leads to an interesting homeostasis: their con- trary effects counteract each other and result in a plateau of the residual strength. To check such a guess, the experimental data of the crack length, spacing and the corresponding residual strength for various values of thermal shock temperature difference $\Delta T$ are listed in Table 3 , which verifies the correlation aforementioned. Such a finding deepens our understanding about the ceramic thermal shock failure.

Table 3 Crack length, spacing and the corresponding residual strength for various values of thermal shock temperature difference $\Delta T$

\begin{tabular}{|c|c|c|c|c|c|}
\hline \multirow{2}{*}{$\Delta T /{ }^{\circ} \mathrm{C}$} & \multirow{2}{*}{ Crack length/mm } & \multirow{2}{*}{ Spacing/mm } & \multicolumn{3}{|c|}{ Residual strength $\sigma_{\mathrm{R}} / \mathrm{MPa}$} \\
\hline & & & Numerical & Experimental & Relative error/\% \\
\hline 280 & $2.978 \pm 0.105$ & $3.672 \pm 0.369$ & 61.409 & $68.231 \pm 2.651$ & 9.999 \\
\hline 330 & $3.200 \pm 0.135$ & $2.918 \pm 0.223$ & 62.601 & $62.379 \pm 9.303$ & 0.355 \\
\hline 380 & $3.378 \pm 0.069$ & $2.766 \pm 0.125$ & 60.698 & $59.818 \pm 10.95$ & 1.471 \\
\hline 480 & $3.626 \pm 0.058$ & $2.446 \pm 0.069$ & 58.746 & $64.558 \pm 12.375$ & 9.003 \\
\hline 580 & $3.849 \pm 0.145$ & $2.320 \pm 0.222$ & 56.284 & $59.811 \pm 7.000$ & 5.897 \\
\hline
\end{tabular}

A comparison between the numerical predictions and experimental results of the residual strength is made, and they are found to agree well with each other as shown in Fig. 6.

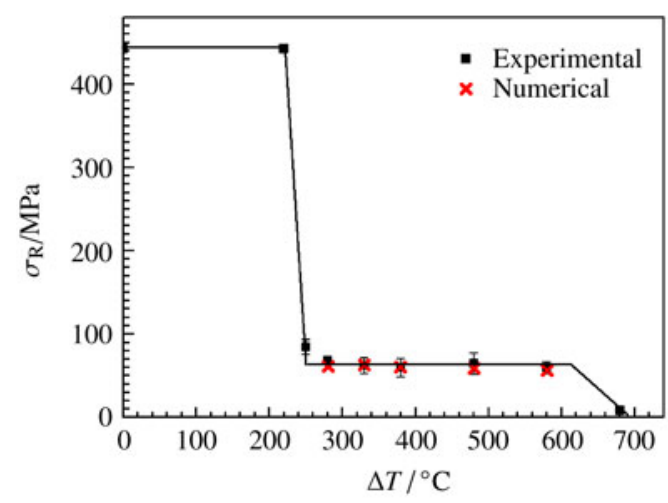

Fig. 6 Numerical and experimental strength value of $\mathrm{Al}_{2} \mathrm{O}_{3}$ ceramic slice at various values of thermal shock temperature difference $\Delta T\left({ }^{\circ} \mathrm{C}\right)$

\section{Conclusions}

(1) A set of thermal shock experiments of ceramics are conducted. The thin specimens exhibit parallel through edge cracks, which permits quantitative measurements of the crack length and density and consequently a deep study on the relation between the residual strength and crack patterns.

(2) The thermal shock cracks evolve with the thermal shock temperature difference. It is found that there is a correlation between the length and density of thermal shock cracks.

(3) The increase of the crack length weakens the residual strength, whereas the increase of the crack density improves it. It is found that in a considerable range the two contrary effects counteract each other and thus lead to a plateau in the residual strength curve. 


\section{References}

1 Danzer, R., Lube, T., Supancic, P., et al.: Fracture of ceramics. Advanced Engineering Materials 10, 275-298 (2008)

2 Padture, N. P., Gell, M., Jordan, E. H.: Thermal barrier coatings for gas-turbine engine applications. Science 296, 280-284 (2002)

3 Kingery, W. D.: Factors affecting thermal stress resistance of ceramic materials. Journal of the American Ceramic Society 38, 3-15 (1955)

4 Hasselman, D. P. H.: Strength behavior of polycrystalline alumina subjected to thermal shock. Journal of the American Ceramic Society 53, 490-495 (1970)

5 Gupta, T. K.: Strength degradation and crack propagation in thermally shocked $\mathrm{Al}_{2} \mathrm{O}_{3}$. Journal of the American Ceramic Society 55, 249-253 (1972)

6 Davidge, R. W., Tappin, G.: Thermal shock and fracture in ceramics. Transactions of the British Ceramic Society 66, 405422 (1967)

7 Coppola, J. A., Krohn, D. A., Hasselman, D. P. H.: Strength loss of brittle ceramics subjected to severe thermal shock. Journal of the American Ceramic Society 55, 481 (1972)

8 Bertsch, B. E., Larson, D. R., Hasselman, D. P. H.: Effect of crack density on strength loss of polycrystalline $\mathrm{Al}_{2} \mathrm{O}_{3}$ subjected to severe thermal shock. Journal of the American Ceramic Society 57, 235-236 (1974)

9 Zhang, Z. P., Shao, Y. F., Song, F.: Characteristics of crack patterns controlling the retained strength of ceramics after thermal shock. Frontiers of Materials Science in China 4, 251-254 (2010)

10 Jin, Z. H., Fu, Y.: Residual strength of metal particulate reinforced ceramics with parallel cracks. Materials Science and Engineering: A 527, 252-257 (2009)

11 Jin, Z. H., Luo, W. J.: Thermal shock residual strength of functionally graded ceramics. Materials Science and Engineering: A 435-436, 71-77 (2006)

12 Jin, Z. H., Feng, Y. Z.: An array of parallel edge cracks with alternating lengths in a strip subjected to a thermal shock. Journal of Thermal Stresses 32, 431-447 (2009)

13 Jin, Z. H., Feng, Y. Z.: Effects of multiple cracking on the residual strength behavior of thermally shocked functionally graded ceramics. International Journal of Solids and Structures 45, 5973-5986 (2008)

14 Song, F., Meng, S. H., Xu, X. H., et al.: Enhanced thermal shock resistance of ceramics through biomimetically inspired nanofins. Physical Review Letters 104, 125502 (2010)

15 Bahr, H. A., Fischer, G., Weiss, H. J.: Thermal-shock crack patterns explained by single and multiple crack-propagation. Journal of Materials Science 21, 2716-2720 (1986)

16 Shao, Y. F., Xu, X. H., Meng, S. H., et al.: Crack patterns in ceramic plates after quenching. Journal of the American Ceramic Society 93, 3006-3008 (2010)

17 Murakami, Y.: Stress Intensity Factors Handbook. Pergamon, Oxford [Oxfordshire], New York (1987) 